\title{
Dural Metastases of Advanced Prostate Cancer Detected by ${ }^{18}$ F-Fluorocholine
}

\author{
Mauro Morassi ${ }^{1}$, Mattia Bonacina ${ }^{2}$, Claudio Bnà ${ }^{1}$, Alberto Zaniboni ${ }^{3}$ and Giordano Savelli ${ }^{2, *}$ \\ 1 Division of Radiology, Fondazione Poliambulanza Istituto Ospedaliero, 25124 Brescia, Italy; \\ mauro.morassi@poliambulanza.it (M.M.); claudio.bna@poliambulanza.it (C.B.) \\ 2 Division of Nuclear Medicine, Fondazione Poliambulanza Istituto Ospedaliero, 25124 Brescia, Italy; \\ mattia.bonacina@poliambulanza.it \\ 3 Department of Medical Oncology, Fondazione Poliambulanza Istituto Ospedaliero, 25124 Brescia, Italy; \\ alberto.zaniboni@poliambulanza.it \\ * Correspondence: giordano.savelli@poliambulanza.it; Tel.: +39-030-351-8027
}

Received: 14 May 2020; Accepted: 5 June 2020; Published: 8 June 2020

check for updates

\begin{abstract}
Prostate cancer with extensive dural metastases is very rare, with only few cases described in the literature. We report one such case of a 74-year-old man with advanced prostate cancer, and in relatively good clinical condition. The patient returned with complaints of headache and diplopia. Fluorocholine $\left({ }^{18} \mathrm{~F}\right)$ chloride $\left({ }^{18} \mathrm{~F}-\mathrm{FCH}\right)$ is an analog of choline in which a hydrogen atom has been replaced by fluorine $\left({ }^{18} \mathrm{~F}\right)$. After crossing the cell membrane by a carrier-mediated mechanism, choline is phosphorylated by choline kinase to produce phosphorylcholine. ${ }^{18} \mathrm{~F}-\mathrm{FCH}$ positron emission tomography-computed tomography (PET/CT) is widely used to stage and restage patients affected by prostate cancer with good sensitivity. ${ }^{18} \mathrm{~F}-\mathrm{FCH} \mathrm{PET} / \mathrm{CT}$ showed disease progression with the onset of multiple skull lesions. Numerous suspicious dural hypermetabolic lesions indicating neoplastic involvement were detected along the fronto-parietal convexities, in the left fronto-orbital region and right lateral wall of the orbit, concerning for metastases in these regions. A contrast-enhanced computed tomography (CECT) scan was performed which showed corresponding enhancing tissue which correlated with the PET findings. The final imaging diagnosis was osteo-dural metastases from prostate cancer associated with poor outcome. Awareness of this pattern of metastases may be of clinical relevance in order to avoid unnecessary invasive diagnostic procedures in groups of patients with a dismal prognosis.
\end{abstract}

Keywords: ${ }^{18}$ F-fluorocholine; prostate cancer; computed tomography; dural metastases; subdural hematomas 
A
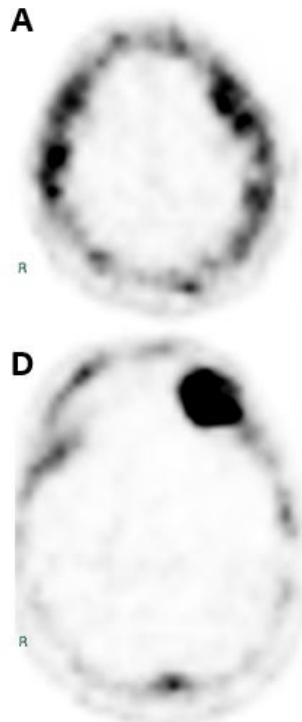

G

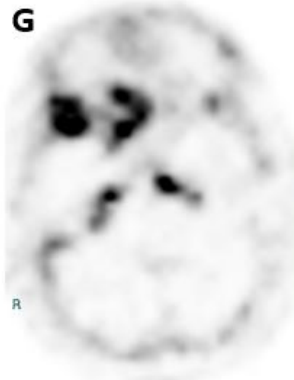

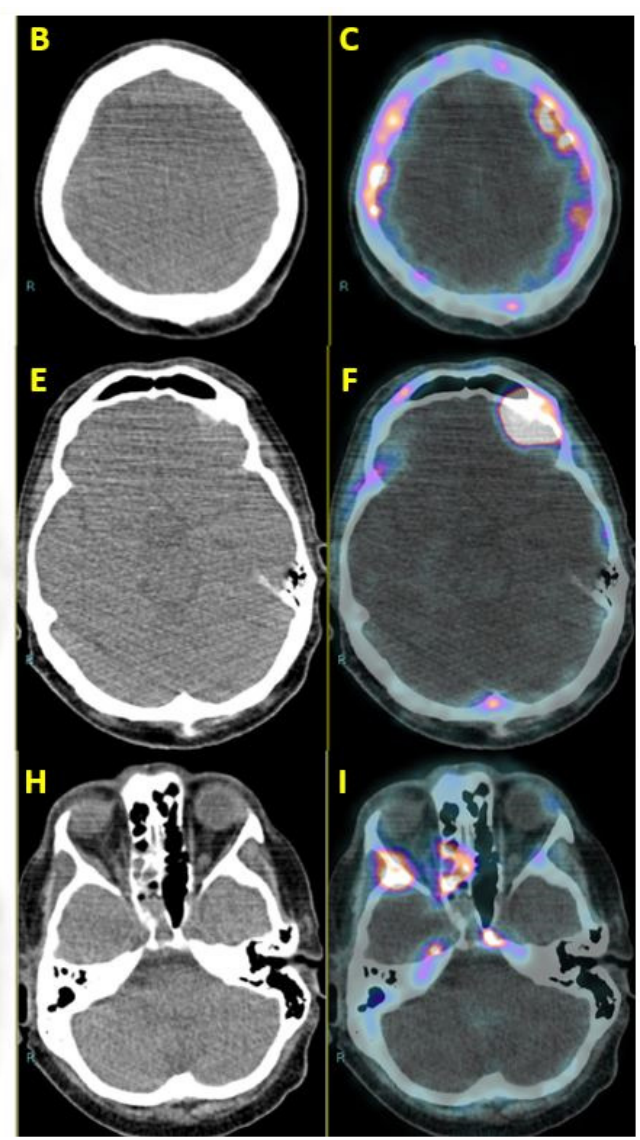

Figure 1. A 74-year-old man was referred to our center for a ${ }^{18} \mathrm{~F}$-fluorocholine $\left({ }^{18} \mathrm{~F}-\mathrm{FCH}\right)$ positron emission tomography-computed tomography (PET/CT). Nearly four years earlier the patient had been diagnosed in another hospital with metastatic prostatic adenocarcinoma (Gleason score $4+3$, $\mathrm{Ct} 2 \mathrm{bN} 0 \mathrm{M} 1$ bone). The tumor was treated with external beam radiation therapy on the prostate bed and bone metastases (pubic bone and sacral lesion), and with androgen deprivation therapy and bisphosphonate. The disease was stabilized for nearly two years (according to the prostate specific antigen, PSA) and ${ }^{18} \mathrm{~F}-\mathrm{FCH}$ levels taken as parameters. Despite the patient's satisfactory clinical conditions, PSA was elevated to $937 \mathrm{ng} / \mathrm{mL}$ (previous value $82 \mathrm{ng} / \mathrm{mL}$ ). The patient was started on enzalutamide $160 \mathrm{mg} /$ day plus zoledronic acid $4 \mathrm{mg}$ every 3 weeks, which resulted in a rapid decline of serum PSA levels $(81 \mathrm{ng} / \mathrm{mL})$. This biochemical response lasted for five months until PSA rose to $371 \mathrm{ng} / \mathrm{mL}$. The patient was then prescribed $20 \mathrm{mg}$ intra-venous docetaxel every three weeks in addition to $5 \mathrm{mg}$ oral prednisone twice a day. Five months after the start of this regimen, the patient began to complain of a progressive and slowly worsening headache and diplopia. The patient's Karnofsky performance scale (KPS) was 80 . A restaging ${ }^{18} \mathrm{~F}-\mathrm{FCH}$ PET/CT was scheduled and performed with a Siemens Biograph mCT nearly one hour after the intravenous administration of $163 \mathrm{MBq}$ of ${ }^{18} \mathrm{~F}-\mathrm{FCH}$. The examination revealed an increased number of hypermetabolic lesions extensively involving the axial skeleton. Moreover, metabolic uptake was noted along the dura of the fronto-parietal convexities (transaxial PET, CT and fused PET/CT, Figure 1: A to C) in the left fronto-orbital region (transaxial PET, $\mathrm{CT}$ and fused PET/CT, Figure 1: $\mathbf{D}$ to F) and the right sphenoid region (transaxial PET, CT and fused PET/CT, Figure 1: $\mathbf{G}$ to I). These findings were strongly suggestive of meningeal metastatic implants. Since the seeding of prostate cancer metastatic cells in this location is highly unusual, a brain magnetic resonance examination was requested for a more detailed evaluation of these lesions. Unfortunately, the patient cannot be imaged due to claustrophobia. 


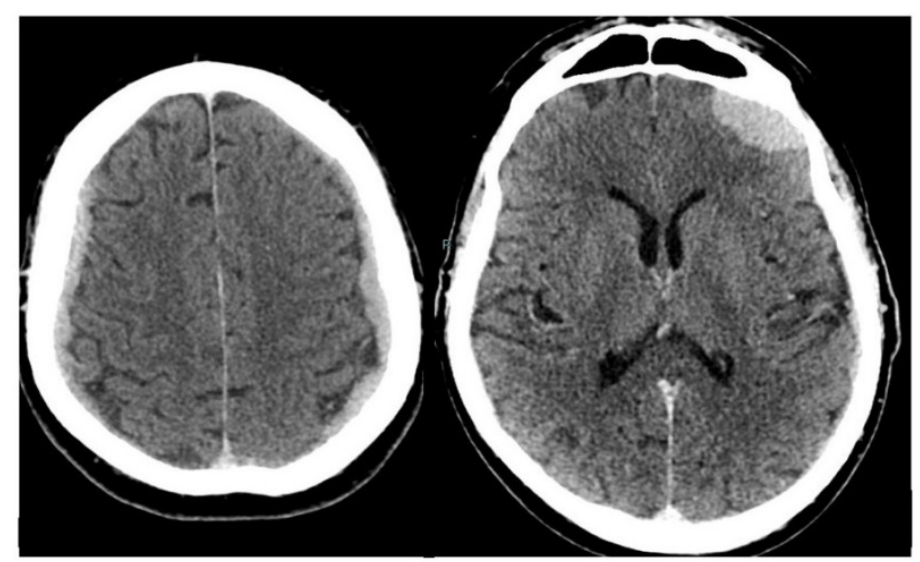

Figure 2. A brain contrast-enhanced computed tomography (CECT) scan was therefore performed and showed extensive pathologic iso-hyperdense tissue along the dura on both sides with intense and homogeneous enhancement following intravenous injection of the contrast medium. The dural-subdural pathologic tissue along the fronto-parietal convexities corresponded to the "en plaque" morphology discussed by Nzokou et al. [1] which may simulate sub-dural hematomas. In the weeks immediately following the CT scan, the patient's clinical conditions rapidly worsened. He was treated with medical therapy with palliative intent. The patient died of arrhythmia approximately one month after the $\mathrm{CT}$. Intracranial prostate cancer metastases are rare with an estimated range varying from $0.6 \%$ to $4.4 \%$ of cases [2]. In an extensive review of 16,280 patients with prostate cancer, only $28(0.001 \%)$ were found to have dural metastases [3], while an autoptic study on 559 patients with hematogenous metastatic diffusion showed meningeal involvement in 5.9\% of cases [4]. Since recent drug trials show improved overall survival for castration-resistant prostate cancer, it seems likely that cases of previously unrecognized dural metastases may become more clinically relevant. Cases of dural and parenchimal metastases from prostate cancer have been reported in the literature [5-9], but data on dural metastases with a bilateral "en plaque" morphological pattern are more limited $[1,10]$. To the best of our knowledge, no reports on ${ }^{18} \mathrm{~F}-\mathrm{FCH}$ appearance in dural metastases from prostate cancer are present in the English scientific literature. As previously stated, the CT appearance of the metastatic lesions along the cerebral convexities was similar to sub-dural hematomas, but the pathologic tissue showed intense enhancement and was hypermetabolic on ${ }^{18} \mathrm{~F}-\mathrm{FCH}$ PET/CT in contrast to hemorrhagic collections. Due to the extensive bilateral metastatic dural-subdural tissue, the patient was not considered eligible for surgery or whole-brain irradiation and received palliative care. In the present case, the use of combined molecular and morphological imaging avoided invasive diagnostic procedures in a patient with a dismal prognosis. The incidence of this unusual metastatic localization may be increasing as therapies for systemic cancer improve and patients survive longer.

Consent for Publication: The patient provided written informed consent for the publication of this case.

Author Contributions: Conceptualization, M.M. and G.S.; methodology, C.B.; validation, M.B. and A.Z. All authors have read and agreed to the published version of the manuscript.

Funding: This research received no external funding.

Acknowledgments: We thank Francesca Poli (Università Cattolica del Sacro Cuore) for proofreading the manuscript.

Conflicts of Interest: The authors declare no conflict of interest.

\section{References}

1. Nzokou, A.; Magro, E.; Guilbert, F.; Fournier, J.Y.; Bojanowski, M.W. Subdural metastasis prostate cancer. J. Neurol. Surg. Rep. 2015, 123-127. [CrossRef] [PubMed] 
2. Ganau, M.; Gallinaro, P.; Cebula, H.; Scibilia, A.; Todeschi, J.; Gubian, A.; Nannavecchia, B.; Signorelli, F.; Pop, R.; Coca, H.-A.; et al. Intracranial Metastases from Prostate Carcinoma: Classification, Management, and Prognostication. World Neurosurg. 2019. [CrossRef] [PubMed]

3. Tremont-Lukats, I.W.; Bobustuc, G.; Lagos, G.K.; Lolas, K.; Kyritsis, A.P.; Puduvalli, V.K. Brain metastasis from prostate carcinoma: The M.D. Anderson Cancer Center experience. Cancer 2003, 98, 363-368. [CrossRef] [PubMed]

4. Bubendorf, L.; Schopfer, A.; Wagner, U.; Sauter, G.; Moch, H.; Willi, N.; Gasser, T.C.; Mihatsch, M.J. Metastatic patterns of prostate cancer: An autopsy study of 1589 patients. Hum. Pathol. 2000, 31, 578-583. [CrossRef] [PubMed]

5. Bradley, L.H.; Burton, M.; Gokden, M.; Serletis, D. Prostate carcinoma mimicking a sphenoid wing meningioma. Int. J. Surg. Case Rep. 2015, 15, 63-65. [CrossRef] [PubMed]

6. Hatzoglou, V.; Patel, G.V.; Morris, M.J.; Curtis, K.; Zhang, Z.; Shi, W.; Huse, J.; Rosemblum, M.; Holodny, A.I.; Young, R.J. Brain Metastases from Prostate Cancer: An 11-Year Analysis in the MRI Era with Emphasis on Imaging Characteristics, Incidence, and Prognosis. J. Neuroimaging 2014, 24, 161-166. [CrossRef] [PubMed]

7. Nayak, L.; Abrey, L.E.; Iwamoto, F.M. Intracranial dural metastases. Cancer 2009, 115, 1947-1953. [CrossRef] [PubMed]

8. Shida, Y.; Hakariya, T.; Miyata, Y.; Sakai, H. Three cases of brain metastasis from castration-resistant prostate cancer. Clin. Case Rep. 2019, 8, 96-99. [CrossRef] [PubMed]

9. Weiner, A.B.; Cortes-Mateus, S.; De Luis, E.; Durán, I. Dural Metastases in Advanced Prostate Cancer: A Case Report and Review of the Literature. Curr. Urol. 2014, 7, 166-168. [CrossRef] [PubMed]

10. Nunno, A.; Johnson, M.D.; Wu, G.; Li, Y.M. Metastatic prostate cancer mimicking a subdural hematoma: A case report and literature review. J. Clin. Neurosci. 2018, 55, 109-112. [CrossRef] [PubMed]

(C) 2020 by the authors. Licensee MDPI, Basel, Switzerland. This article is an open access article distributed under the terms and conditions of the Creative Commons Attribution (CC BY) license (http://creativecommons.org/licenses/by/4.0/). 